\title{
AWARENESS OF MOTHER TO CHILD HIV TRANSMISSION AMONG WOMEN ATTENDING ANTENATAL CLINIC, SMIMER, SURAT
}

\author{
Patel P B ${ }^{1}$, Nayak S² \\ ${ }^{1}$ Assistant Professor, ${ }^{2}$ Assistant Professor, Department of Community Medicine \\ Surat Municipal Institute of Medical Education and Research (SMIMER), Surat, India
}

\begin{abstract}
The study was conducted among 946 women attending antenatal clinic in SMIMER teaching hospital during 2008 to know their awareness regarding various aspects of mother-to-child transmission (MTCT) of HIV and it was found that though the general awareness of HIV is high, awareness of MTCT and its prevention is low which need to be improved through focused IEC campaign.
\end{abstract}

Background : More than $90 \%$ of HIV infections in children aged $<15$ years are due to mother-to-child transmission (MTCT). The MTCT may reverse the gains of the child survival strategy in the country. Awareness of HIV and MTCT among antenatal women plays crucial role in preventing MTCT.

Objective : To evaluate the awareness and knowledge of HIVIAIDS, MTCT of HIV and the methods to prevent MTCT of HIV.

Methods : This is a descriptive cross sectional study carried out among antenatal women at the SMIMER Teaching Hospital during 2008.

Results : Out of 946 women interviewed, $78 \%$ had heard of HIVIAIDS and main sources of information were television $(48.8 \%)$ and radio (37.8\%). Ninety-one percent of women were aware of MTCT of HIV. Trans-placental route (41\%) was the commonly identified route of transmission. Awareness of HIVIAIDS, HIV co-existence with pregnancy and Mother to child transmission was significantly higher among women with at least secondary education $(P<0.05)$. The level of knowledge and perceptions of MTCT of HIV is inadequate.

Conclusion : There is an urgent need to scale up HIV awareness programme focusing on mother-to-child transmission in the region.

Keywords : Awareness, education, mother-to-child transmission, prevention, HIV

\section{INTRODUCTION}

India accounts for about $7 \%$ of all HIVIAIDS cases in the world. ${ }^{1}$ Globally, women constitute $48 \%$ of adults infected with HIV; in India, they constitute $39 \%$. The prevalence is highest among productive young people between the ages of 20 and 29 years, with $60 \%$ of new infections occurring in the $15-25$ years

\section{Correspondence to}

Dr. Prakash B. Patel, Assistant Professor

Department of Community Medicine, Surat Municipal Institute of Medical Education and Research (SMIMER), Surat - 395010,

Email: drpbpatel@gmail.com age group.,3 Heterosexual transmissions account for more than $80 \%$ of all infections. ${ }^{4}$ The pandemic is having a serious effect on the reproductive health of women in India.

There is an increase in the number of children infected with HIV in recent years as the number of HIVpositive women has increased. ${ }^{1}$ More than $90 \%$ of HIV infections in children aged less than 15 years are due to mother-to-child transmission of HIV. ${ }^{5}$ In many developed countries, testing, antiretroviral therapy and infant-feeding modifications have been effectively used to eliminate mother-to-child transmission of 
HIV. ${ }^{6,7}$ In countries like India, HIV continues to be a problem due to lack of information, testing services and antiretroviral therapy. ${ }^{1}$ The high prevalence of mother-to-child transmission has reversed the gains of the child survival strategy in the country. There is an urgent need to combat this menace.

The "Prevention of Mother-to-Child Transmission of HIV" service was started in October 2003 at SMIMER hospital, Surat. Following the designation of this center as a service center for the program of prevention of mother-to-child transmission, a counselor appointed to run the centre. The current study was undertaken to assess the knowledge and awareness about HIVI AIDS and mother-to-child transmission among women attending the antenatal OPD. The information obtained would influence the counseling and education of patients and the community about HIVIAIDS.

\section{MATERIAL AND METHODS}

The study was carried out at the antenatal outpatient department of SMIMER Teaching Hospital, Surat, from $1^{\text {st }}$ January 2008 to $30^{\text {th }}$ December 2008. Women included in the study were in first contact with HIV facilities, which was at our center, before any form of counseling. The instrument used was a questionnaire designed to assess awareness of the women about HIVI AIDS, evaluate their knowledge of possible routes of transmission, particularly mother-to-child transmission, and measures to prevent vertical transmission from mother to child. It included sociodemographic information such as age, marital status and level of education. Questions were asked on whether they were aware of HIVIAIDS, the routes of transmission of HIV, the possibility of HIV coexisting with pregnancy and transmission to the infants, the timing of transmission from mother to child, measures to prevent mother-to-child transmission; and whether they felt that a healthy person could be infected with HIV. The questionnaire was then pre-tested for comprehensibility, appropriateness of language, sensitivity of questions and average duration of administration. The interviewers were trained in interviewing techniques, were aware of the eligibility criteria of respondents and were capable of providing a detailed explanation of each question in the local language. Ethical approval was obtained from the institutional ethical committee of the SMIMER Teaching Hospital, Surat.

\section{Sample size}

Sample size was calculated from the expression $n$ $=4 \mathrm{pq} / \mathrm{L}^{2}$, where $\mathrm{p}$ is expected frequency of factor under study and $q$ is ' $1-p$ '. The confidence level was specified as $95 \%$, and the tolerable error margin $(L)$ was $5 \%$. Specifications for $p$ were determined based on the study objectives. The largest sample size that satisfied all objectives was used and a sample of 788 respondents was needed $(p=67$, which was the prevalence of awareness among urban women of transmission of HIV from mother to her infants in NFHS $3{ }^{8}$ The sample size was adjusted to compensate for a non-response rate of $10 \%$. The final, minimum sample size was 867 .

\section{Data analysis}

Data was analyzed using Epi-info for the descriptive aspects of analysis, and frequency distributions were generated for all categorical variables. Means and standard deviations were determined for quantitative variables. The Chi-square test was applied for comparisons of proportions and for evaluating association of categorical variables. Statistical significance was said to be achieved when the $\mathrm{P}$ value was $<0.05$.

\section{RESULT}

A total of 946 women attended the antenatal clinic and given consent were interviewed during the study period. The age range of the respondents was 17- 42 years, with a mean age of 27.2 (SD 4.71) years. Nine hundred thirty one respondents were married, and $516(54.5 \%)$ had at least secondary level of education (Table 1).

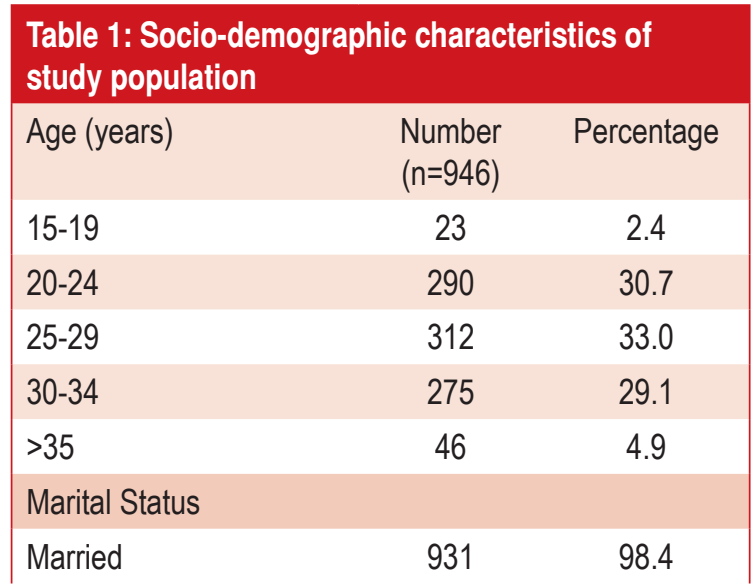




\begin{tabular}{|lcc|} 
Divorced & 9 & 1.0 \\
Widowed & 6 & 0.6 \\
Educational level & & \\
Illiterate & 238 & 25.2 \\
Primary & 192 & 20.3 \\
Secondary & 424 & 44.8 \\
Graduate \& above & 92 & 9.7 \\
\hline
\end{tabular}

Table 2 shows the awareness and knowledge of HIVI AIDS among the respondents. $78 \%$ respondents interviewed were aware of HIVIAIDS, and among them $55 \%$ had been aware of the disease for more than 5 years. The main sources of information included television (48.8\%), radio $(37.8 \%)$, public awareness campaign (35.3\%) and health workers (35.4\%). All women who have heard of HIVIAIDS identified sexual intercourse as a route of transmission of HIV. Sharing of sharps (needles, razors) and blood transfusion were identified as additional routes of transmission by $17 \%$ and $48 \%$ of the respondents, respectively. Higher proportion (62\%) of the respondents think that HIV infected person cannot be look healthy.

\begin{tabular}{|c|c|c|}
\hline Heard of HIVIAIDS ( $n=946)$ & Number & Percentage \\
\hline Yes & 736 & 77.8 \\
\hline No & 210 & 22.2 \\
\hline \multicolumn{3}{|c|}{ Duration of awareness ( $n=736$ ) } \\
\hline$<5$ years & 332 & 45.1 \\
\hline$>5$ years & 404 & 54.9 \\
\hline \multicolumn{3}{|c|}{ Source of information $(n=736)$} \\
\hline Television & 359 & 48.8 \\
\hline Radio & 278 & 37.8 \\
\hline Public campaign / rally & 260 & 35.3 \\
\hline Health workers & 251 & 34.1 \\
\hline News paper & 233 & 31.7 \\
\hline Friend/relative/neighbor & 179 & 24.3 \\
\hline \multicolumn{3}{|c|}{ Route of transmission $(n=736)$} \\
\hline Sexual intercourse & 736 & 100.0 \\
\hline $\begin{array}{l}\text { sharing/reusing needle/ } \\
\text { syringe }\end{array}$ & 128 & 17.4 \\
\hline Blood transfusion & 350 & 47.6 \\
\hline \multicolumn{3}{|c|}{ Infected person can be healthy $(n=736)$} \\
\hline Yes & 78 & 10.6 \\
\hline No & 457 & 62.1 \\
\hline Don't know & 201 & 27.3 \\
\hline
\end{tabular}

Table 3 shows that majority (91\%) of the respondents were aware that HIV could coexist with pregnancy, but only $62 \%$ were aware of mother-to-child transmission of HIV. The observed difference between their two proportions was statistically significant $(P<0.05)$.

\begin{tabular}{|c|c|c|}
\hline Knowledge & $\begin{array}{l}\text { Number } \\
(n=736)\end{array}$ & Percentage \\
\hline \multicolumn{3}{|c|}{ HIV co-exist with pregnancy } \\
\hline Yes & 673 & 91.4 \\
\hline No & 41 & 5.6 \\
\hline Don't know & 22 & 3.0 \\
\hline \multicolumn{3}{|c|}{ Mother to child transmission } \\
\hline Yes & 453 & 61.5 \\
\hline No & 117 & 15.9 \\
\hline Don't know & 166 & 22.6 \\
\hline \multicolumn{3}{|c|}{ Route of transmission to child } \\
\hline Placenta & 271 & 59.8 \\
\hline Vaginal Delivery & 180 & 39.7 \\
\hline Caesarean section & 188 & 41.5 \\
\hline Breast feeding & 240 & 53.0 \\
\hline Don't know & 95 & 21.0 \\
\hline \multicolumn{3}{|c|}{ Method of Preventing MTCT } \\
\hline ART in Pregnancy & 77 & 17.0 \\
\hline ART during labor & 50 & 11.0 \\
\hline $\begin{array}{l}\text { Delivery by } \\
\text { caesarean }\end{array}$ & 28 & 6.2 \\
\hline $\begin{array}{l}\text { Special medication } \\
\text { to newborn }\end{array}$ & 36 & 7.9 \\
\hline no breast feeding & 110 & 24.3 \\
\hline Don't know & 265 & 58.5 \\
\hline
\end{tabular}

Trans-placental route as a mode of mother-tochild transmission of HIV was known by $60 \%$ of the respondents. A significantly lower proportion of the respondents identified vaginal delivery and breastfeeding as routes of HIV transmission ( $40 \%$ and $53 \%$, respectively; $P<0.05$ ).

Cesarean section was believed to be a route of transmission by $188(41 \%)$ respondents. This proportion was significantly higher than the $39 \%$ of the respondents that identified vaginal delivery as a route of mother-to-child transmission of HIV $(P<0.05)$. Ninety-five $(21 \%)$ women could not identify any route of mother-to-child transmission. The use of antiretroviral drugs in pregnancy and avoidance of breastfeeding were identified as methods of reducing mother-to-child transmission of HIV by only $17 \%$ 
and $24 \%$ of the respondents, respectively. Delivery by cesarean section was identified as a method of prevention of mother-to-child transmission by only 28 $(6 \%)$ respondents. A significantly higher proportion of respondents $(58 \%, \mathrm{P}<0.05)$ did not know any method to prevent mother-to-child transmission of HIV.

Table 4 shows the knowledge about mother-to- child transmission of HIV among women with no or primary education as compared with women who had at least secondary education. Awareness of HIVIAIDS, HIV co-existence with pregnancy and Mother to child transmission was higher among women with at least secondary education. The observed differences were statistically significant $(P<0.05)$.

\begin{tabular}{|c|c|c|c|}
\hline $\begin{array}{l}\text { Heard of HIVI } \\
\text { AIDS } \\
(n=946)\end{array}$ & $\begin{array}{l}\text { No or Primary } \\
\text { education }\end{array}$ & $\begin{array}{l}\text { At least } \\
\text { Secondary } \\
\text { education }\end{array}$ & $P$ value \\
\hline Yes & $317(73.7)$ & $419(81.2)$ & 0.005 \\
\hline No & $113(26.3)$ & $97(18.8)$ & \\
\hline \multicolumn{4}{|c|}{ HIV co-exist with pregnancy ( $n=736$ ) } \\
\hline Yes & $246(88.8)$ & $427(93.0)$ & 0.047 \\
\hline No & $11(4.0)$ & $30(6.5)$ & \\
\hline Don't know & $20(7.2)$ & $2(0.4)$ & \\
\hline \multicolumn{4}{|c|}{ HIV transmit from Mother to her child $(n=736)$} \\
\hline Yes & $53(19.1)$ & $400(87.1)$ & $<0.0001$ \\
\hline No & $68(24.5)$ & $49(10.7)$ & \\
\hline Don't know & $156(56.3)$ & $10(2.2)$ & \\
\hline
\end{tabular}

\section{DISCUSSION}

More than three forth of women in this study were aware of HIVIAIDS, and the majority also demonstrated knowledge of mode of transmission and the course of the disease. This is commendable and may be attributed to many factors, including the high level of education of the respondents. Such high levels of awareness have been reported in Delhi ${ }^{9}$ and Pune ${ }^{10}$ in India and in other parts of the world. ${ }^{6,11,12}$ The high levels of awareness and knowledge of HIVIAIDS reported in most parts of India may be the contributory factor for steady HIV prevalence among pregnant women, as shown by sentinel surveys. ${ }^{2}$ The main media of information on HIV/ AIDS among women in this study were television, radio, health worker and public rallies. Mass media communications have been quite successful in increasing knowledge about HIVI AIDS and have been the first source of knowledge about HIVIAIDS for many.

Sexual intercourse was identified as a route of transmission by all the respondents who were aware of HIVIAIDS. This agrees with a worldwide trend in which sexual intercourse is the route of transmission mostly known to respondents. ${ }^{9,10,11,12}$ Blood transfusion and the sharing of razors and other sharp objects were identified by $48 \%$ and $17 \%$ of respondents, respectively, in this study as routes of transmission. It reflects lower level of awareness of HIV transmission by these routes. ${ }^{9,10}$

Ninety-one of the respondents were aware that HIV infection could coexist with pregnancy, while a significantly lower proportion $(61 \%)$ of respondents were aware of mother-to-child transmission of HIV. The study also reveals that illiterate or literate up to primary level respondents had poor in their awareness of mother-to-child transmission of HIV. Furthermore, specific knowledge of routes of transmission or measures available to prevent transmission was low. Similar low levels of knowledge were reported in other parts of India9,10 and Nigeria. ${ }^{11}$

More than half of the women in this study did not know of any method of preventing mother-to-child transmission of HIV. Avoiding breastfeeding was identified by $24 \%$ of the respondents as a means of preventing transmission from mother to child, while only $6.2 \%$ of the respondents mentioned cesarean section as a method of preventing mother-to-child transmission of HIV. It is known that breastfeeding contributes $30-40 \%$ of vertical transmissions ${ }^{1}$. This is a noteworthy and contemporary issue, since in India and other developing countries, breastfeeding is the cultural norm and exclusive breastfeeding is advocated because of high infant mortality and morbidity from diarrheal diseases and malnutrition. Women are likely to opt for breastfeeding to avoid being stigmatized as HIVIAIDS victims. However, there is a need for government and nongovernmental policies that will ensure a sustainable and effective breast milk substitute supply and its utilization by infants of HIV-positive women, just as antiretroviral drugs are currently being made available to these women. 
This study provides information about knowledge of mother-to-child transmission of HIV and its prevention among women targeted for intervention in a highprevalent urban area. The women in this study were interviewed at their first visit to the antenatal clinic. Some of the women could have had some information prior to presentation to the clinic. This study therefore has a reflection on the larger community.

In our locality, the opinion of the male partners strongly influences the adoption of health policies and programs by women.

For community education, a public media campaign should dwell more on the aspect of prevention of mother-to-child transmission. There is also the need for increased collaboration with HIVIAIDS prevention programs. Finally, a more comprehensive evaluation of knowledge and attitudes of both men and women in the community about HIVI AIDS and mother-tochild transmission will provide added information for establishing community intervention programs.

\section{REFERENCES}

1. Joint United Nations Programme on HIVIAIDS (UNAIDS). Report on the global AIDS epidemic 2008. Available from: http://www.unaids.org/en/ KnowledgeCentre/HIVData/GlobalReport/2008/2008_ Global_report.asp [accessed on 2010 Mar 16].

2. National AIDS Control Organisation (NACO). Annual HIV Sentinel Surveillance Country Report 2006. Available from: http://www.nacoonline.org/upload/ [accessed on $2010 \mathrm{Mar} 16]$.

3. US Aids international development (USAID). India country profile (HIVIAIDS), 2008. Available from: http://www.usaid.gov/locations/asia/countries/india [accessed on 2010 March 16].

4. World Health Organization, Regional Office for SouthEast Asia. HIV IAIDS in the South-East Asia Region 2009, New Delhi, India 2009. p17
5. Giaquinto C, Rage E, Giarcoment V, Rampson O, Elia DR. Mother to child transmission current knowledge and ongoing studies. Int J Gynecol Obstet. 1998;68:161-5

6. Granich $\mathrm{R}$, et al. Highly active antiretroviral treatment for the prevention of HIV transmission. J Int AIDS Soc. 2010;13(1):1.

7. Becquet $R$, et al. Universal antiretroviral therapy for pregnant and breast-feeding HIV-1-infected women: towards the elimination of mother-to-child transmission of HIV-1 in resource-limited settings. Clin Infect Dis. 2009 ;49(12):1936-45 Review.

8. International Institute for Population Sciences (IIPS) and Macro International. National Family Health Survey (NFHS-3), 2005-06: India: Volume I. Mumbai: IIPS. 2007; p331

9. Rahbar T, Garg S, Tripathi R, Gupta VK, Singh MM. Knowledge, attitude, behavior and practice (KABP) regarding HIV/AIDS among pregnant women attending PPTCT programme in New Delhi. J Commun Dis. 2007;39(3):179-84.

10. Kunte A, Misra V, Paranjape R, Mansukhani N, Padbidri V, Gonjari S, et al. HIV seroprevalence \& awareness about AIDS among pregnant women in rural areas of Pune district, Maharashtra, India. Indian J Med Res. 1999;110:115-22.

11. Harns G, Mayer A, Karcher H. Prevention of mother to child transmission of HIV in Kenya, Tanzania and Uganda: Report to Government of Tanzania PMTCT project. International coordination office. Berlin, Germany: 2003; pp1-26.

12. Lum $\mathrm{H}$, Isichei $\mathrm{C}$, Isichei W. Expansion of HIV screening and antiretroviral treatment programme in a resource poor setting, results from a faith based organization in Jos, Nigeria. Afr Health Sci 2007;7:101-7

(Source of Support: Nil, Conflict of Interest: none declared.) 